\title{
Leg and arm lactate and substrate kinetics during exercise
}

\author{
G. VAN HALL, ${ }^{1}$ M. JENSEN-URSTAD,${ }^{2}$ H. ROSDAHL, ${ }^{3}$ \\ H.-C. HOLMBERG,${ }^{3}$ B. SALTIN, ${ }^{1}$ AND J. A. L. CALBET ${ }^{1}$ \\ ${ }^{1}$ The Copenhagen Muscle Research Centre, University Hospital, \\ DK-2100 Copenhagen, Denmark; and the Departments of ${ }^{2}$ Cardiology and \\ ${ }^{3}$ Physiology-Pharmacology, Karolinska Institute, 17177 Stockholm, Sweden
}

Submitted 20 June 2002; accepted in final form 5 September 2002

Van Hall, G., M. Jensen-Urstad, H. Rosdahl, H.-C. Holmberg, B. Saltin, and J. A. L. Calbet. Leg and arm lactate and substrate kinetics during exercise. Am J Physiol Endocrinol Metab 284: E193-E205, 2003. First published September 11, 2002; 10.1152/ajpendo.00273.2002.-To study the role of muscle mass and muscle activity on lactate and energy kinetics during exercise, whole body and limb lactate, glucose, and fatty acid fluxes were determined in six elite cross-country skiers during roller-skiing for $40 \mathrm{~min}$ with the diagonal stride (Continuous Arm + Leg) followed by $10 \mathrm{~min}$ of double poling and diagonal stride at 72-76\% maximal $\mathrm{O}_{2}$ uptake. A high lactate appearance rate $\left(R_{a}, 184 \pm 17\right.$ $\mu \mathrm{mol} \cdot \mathrm{kg}^{-1} \cdot \mathrm{min}^{-1}$ ) but a low arterial lactate concentration $(\sim 2.5 \mathrm{mmol} / \mathrm{l})$ were observed during Continuous Arm + Leg despite a substantial net lactate release by the arm of $\sim 2.1$ $\mathrm{mmol} / \mathrm{min}$, which was balanced by a similar net lactate uptake by the leg. Whole body and limb lactate oxidation during Continuous Arm + Leg was $\sim 45 \%$ at rest and $\sim 95 \%$ of disappearance rate and limb lactate uptake, respectively. Limb lactate kinetics changed multiple times when exercise mode was changed. Whole body glucose and glycerol turnover was unchanged during the different skiing modes; however, limb net glucose uptake changed severalfold. In conclusion, the arterial lactate concentration can be maintained at a relatively low level despite high lactate $R_{a}$ during exercise with a large muscle mass because of the large capacity of active skeletal muscle to take up lactate, which is tightly correlated with lactate delivery. The limb lactate uptake during exercise is oxidized at rates far above resting oxygen consumption, implying that lactate uptake and subsequent oxidation are also dependent on an elevated metabolic rate. The relative contribution of whole body and limb lactate oxidation is between 20 and $30 \%$ of total carbohydrate oxidation at rest and during exercise under the various conditions. Skeletal muscle can change its limb net glucose uptake severalfold within minutes, causing a redistribution of the available glucose because whole body glucose turnover was unchanged.

lactate dehydrogenase; cross-country skiing; tracers

AS EARLY AS 1907, Fletcher and Hopkins (11) not only provided definitive evidence of the relation between muscle activity and production of lactic acid in the

Address for reprint requests and other correspondence: G. van Hall, The Copenhagen Muscle Research Centre, Rigshospitalet, Section 7652, 9 Blegdamsvej, DK-2100 Copenhagen Ø, Denmark (E-mail: gvhall@cmrc.dk). amphibian skeletal muscle, but they also concluded that skeletal muscles possess the requisite chemical mechanisms for the removal of lactic acid once formed. Despite this early finding, lactate was long considered a metabolic end product, that is, lactate produced during muscle contraction and released into the circulation for subsequent uptake by the liver for recycling via gluconeogenesis. The importance of skeletal muscle in lactate clearance in humans became clear from experiments starting in the late $1950 \mathrm{~s}$. It was shown that, during exercise, lactate was taken up by nonactive skeletal muscles $(1,7,12)$. Furthermore, when the arterial lactate concentration was also elevated, active skeletal muscles cleared lactate $(12,26,30)$, and when two-legged cycle ergometer exercise was performed with one leg having a normal and the other a low glycogen content, the leg with the normal glycogen content released lactate, whereas lactate was taken up by the leg with the low glycogen content $(10,13)$. In addition, the utilization of lactate by skeletal muscle appeared to be higher when light exercise was performed compared with complete rest $(14,24,26,27)$. From these studies it was concluded that skeletal muscles not only produce lactate, but they are also the major tissue for lactate removal from the circulation. Further studies with lactate isotopes have shown a simultaneous limb lactate uptake and release at rest and during exercise $(15,16,34)$. This suggests a dynamic situation, with exchange of lactate as a carbohydrate source between fibers within the same muscle but also from one muscle group to another, whether actively contracting or not. To study the magnitude of such fluxes, six elite cross-country skiers were studied during roller skiing. This exercise model provides a unique opportunity to investigate systemic and skeletal muscle lactate and energy kinetics during exercise with the majority of the body's skeletal muscle mass engaged in the exercise. Cross-country skiers have a similar training status in the upper and the lower body muscles, and to them roller-skiing is a natural mode of exercise with substantial changes in skeletal muscle

The costs of publication of this article were defrayed in part by the payment of page charges. The article must therefore be hereby marked "advertisement" in accordance with 18 U.S.C. Section 1734 solely to indicate this fact. 
activity without a change in the total work done by the whole body. Thus the skiers were studied during skiing with the diagonal stride technique, in which both the legs and arms are active, and during the double poling technique, in which mainly the arms provide the speed-generating force. Leg and arm lactate, glucose, and fatty acid kinetics were determined by measurements across a leg and an arm for metabolites, tracer dilution, and blood flow at rest and during the two modes of skiing. In addition, muscle biopsies were obtained from the vastus lateralis and deltoid for enzyme activities and lactate dehydrogenase isoform patterns.

\section{METHODS}

\section{Subjects}

Six Swedish elite cross-country skiers, age 24 (20-31) yr, height $181(174-190) \mathrm{cm}$, and weight $74(71-83) \mathrm{kg}$, participated in the study. Maximal oxygen uptake $\left(\mathrm{V}_{2}{ }_{2}\right.$ max $)$ was $5.2(4.9-5.8) \mathrm{l} / \mathrm{min}$ or $71(65-74) \mathrm{ml} \cdot \mathrm{kg}^{-1} \cdot \mathrm{min}^{-1}$, assessed during an incremental intensity test with diagonal stride on roller skis on a modified treadmill as used in the actual study. One additional skier was studied with a slightly different exercise protocol. This subject has been excluded except for the data on the muscle biopsies. The subjects were informed about the possible risks and discomfort involved before their voluntary consent to participate was given. The study was performed according to the Declaration of Helsinki and was approved by the Ethical Committee of the Karolinska Institute, Stockholm, Sweden.

\section{Protocol}

On the day of the experiment, the athletes reported to the laboratory at $8 \mathrm{AM}$, and catheters were placed under local anesthesia. Positioning of the catheters is depicted in Fig. 1. A Swan-Ganz triple-lumen catheter was inserted into an antecubital vein and under fluoroscopic guidance was advanced into the subclavian vein $\sim 5 \mathrm{~cm}$ before the merger with the jugular vein. One lumen was used for blood sampling and another for infusion of ice-cold saline for blood flow measurements with the thermodilution technique (2). The femoral arterial catheter (18-gauge, Ohmeda, Wiltshire, UK) was inserted $2-5 \mathrm{~cm}$ below the inguinal ligament and advanced $5-10 \mathrm{~cm}$ in the proximal

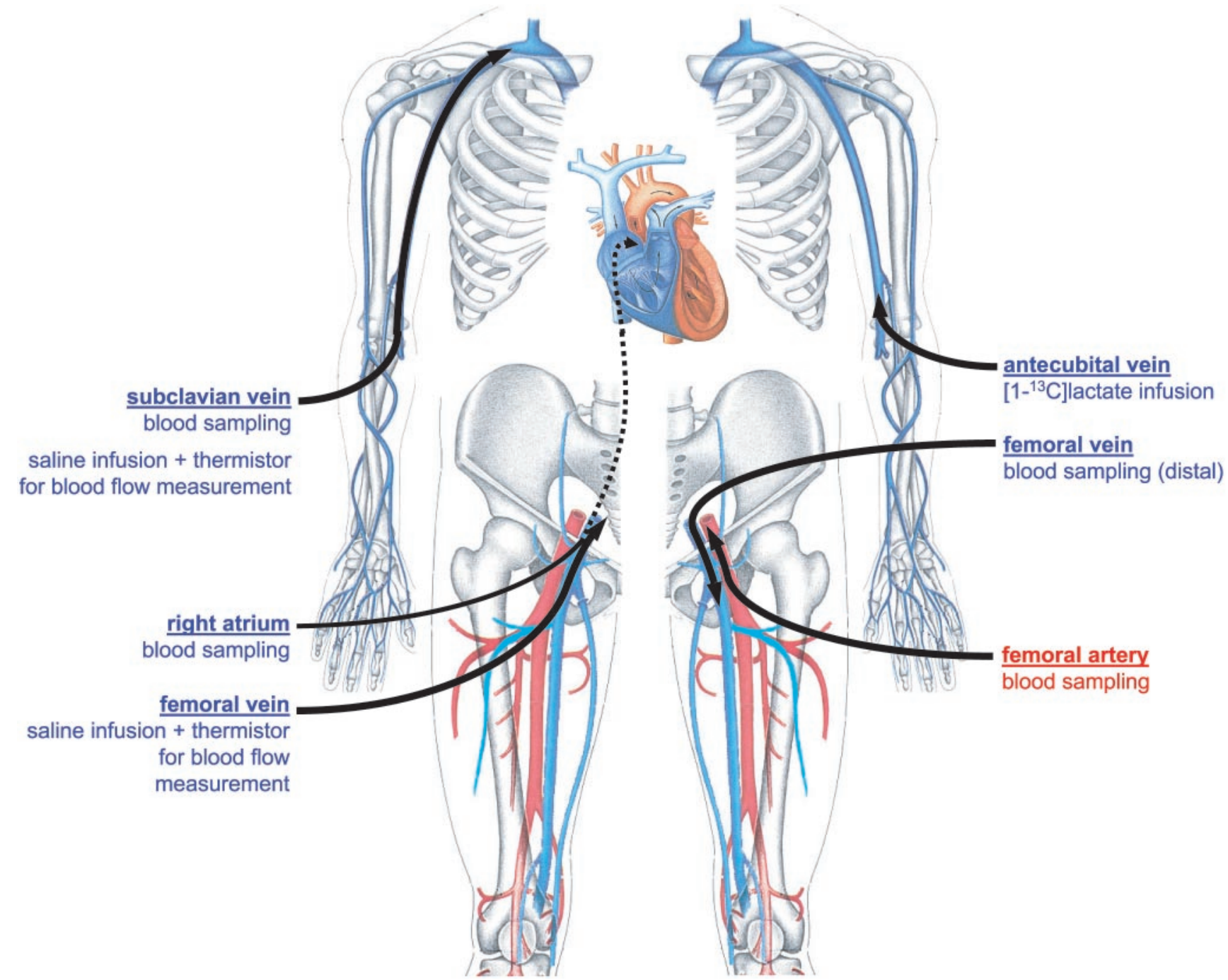

Fig. 1. Position and function of the catheters. 
direction. Another catheter was inserted into the right femoral vein and under fluoroscopic guidance advanced to the right atrium. In the left femoral vein, a venous catheter with side holes (radiopack TFE, Cook, Bjaerverskov, Denmark) was inserted and advanced $\sim 5 \mathrm{~cm}$ proximal to the inguinal ligament. A thermistor was inserted through the venous catheter for blood flow measurements by the constant infusion thermodilution technique (2). Another catheter in the femoral vein was inserted $\sim 2 \mathrm{~cm}$ below the inguinal ligament and advanced $\sim 5 \mathrm{~cm}$ in the distal direction for blood sampling. The catheters can slide out during exercise. To prevent this, catheters were fixed to the skin with stitches. After the catheterization procedures, the athletes remained in the supine position until preparations were started for the exercise bout. Thirty minutes after the final placement of the catheters, blood samples were obtained for assessment of background enrichment of lactate and $\mathrm{CO}_{2}$. Immediately after the background samples were taken, a bolus of $\mathrm{H}^{13} \mathrm{CO}_{3}(1.5 \mu \mathrm{mol} / \mathrm{kg})$ was given, and a primed constant infusion of tracers (Cambridge Isotope Laboratories, Andover, MA) was started of $\left[1{ }^{13} \mathrm{C}\right]$ lactate $\left(0.79 \mu \mathrm{mol} \cdot \mathrm{min}^{-1} \cdot \mathrm{kg}^{-1}\right.$, prime $\left.13 \mu \mathrm{mol} / \mathrm{kg}\right)$, $\left[1,1,2,3,3-{ }^{2} \mathrm{H}_{5}\right]$ glycerol $\left(0.14 \mu \mathrm{mol} \cdot \mathrm{min}^{-1} \cdot \mathrm{kg}^{-1}\right.$, prime 1.5 $\mu \mathrm{mol} / \mathrm{kg})$ and $\left[6,6{ }^{2} \mathrm{H}_{2}\right]$ glucose $\left(0.38 \mu \mathrm{mol} \cdot \mathrm{min}^{-1} \cdot \mathrm{kg}^{-1}\right.$, prime $17.6 \mu \mathrm{mol} / \mathrm{kg}$ ). After subjects had spent $1 \mathrm{~h}$ in the supine position, a biopsy was taken under local anesthesia of the vastus lateralis in seven skiers. From three of them, an additional biopsy was taken from the deltoid. Two hours after the start of the constant $\left[1-{ }^{13} \mathrm{C}\right]$ lactate infusion, three resting blood samples were obtained $15 \mathrm{~min}$ apart. In addition, femoral and subclavian venous blood flows were measured just before blood sampling. After the last resting blood sample had been taken, the subjects were seated on a chair placed on the treadmill (Refox, Falun, Sweden) to prepare for exercise. This preparation took between 30 and $50 \mathrm{~min}$ and included connection of extension lines to the catheters and fixation of the lines. The lines for blood sampling were fixed on the back of the harness, which was worn to protect subjects from injuries in case they fell during skiing (Fig. 2). At the start of the exercise, the continuous infusion of $\left[1-{ }^{13} \mathrm{C}\right]$ lactate was increased fourfold, and the continuous infusion of $\left[1,1,2,3,3-{ }^{2} \mathrm{H}_{5}\right]$ glycerol and $\left[6,6-{ }^{2} \mathrm{H}_{2}\right]$ glucose was increased twofold.

Classical skiing involves different techniques. The diagonal stride involves both the arms and the legs and is used uphill (Fig. 2). The double poling technique mainly involves the upper body (arms) and is used on flat terrain and slightly uphill. The protocol consisted of $40 \mathrm{~min}$ of continuous diagonal style (Continuous Arm + Leg), followed without breaks by $10 \mathrm{~min}$ of double poling (Arm) and $10 \mathrm{~min}$ of diagonal stride (Arm + Leg). Blood samples were taken after 21, 24, and $36 \mathrm{~min}$ of continuous Arm + Leg, and then $~ 5-7 \mathrm{~min}$ after the start of Arm and Arm + Leg skiing. After the study was finished, the subjects were moved to the operation theater, and the catheter positions in the subclavian vein and right atrium were checked with fluoroscopy; no catheter was found displaced during the study.

Blood was sampled anaerobically in a heparinized syringe and immediately analyzed for hemoglobin, oxygen saturation (OSM3 hemoxymeter, Radiometer, Copenhagen, Denmark), blood pH, $\mathrm{CO}_{2}$, and $\mathrm{O}_{2}$ tension (ABL5, Radiometer). Another blood sample was taken, and the blood was collected in ice-cold tubes that contained $10 \mu \mathrm{l}$ of $0.33 \mathrm{M}$ EDTA $/ \mathrm{ml}$ of blood and was immediately centrifuged at $4^{\circ} \mathrm{C}$ for $10 \mathrm{~min}$ and stored at $-50^{\circ} \mathrm{C}$ until analysis.

\section{Analytical Procedures}

Plasma was analyzed enzymatically for lactate, glucose (Roche Unikit, Neuss, Germany), and free fatty acids (NEFA-C kit, Wako Chemical) on an automatic analyzer (Cobas Fara, Roche, Basel, Switzerland).

Lactate, glucose, and glycerol enrichment was measured by gas chromatography-mass spectrometry (GC-MS, Finnigan Automass II and III, Paris, France; GC column, CP-SIL 8CB, Chrompack, Middelburg, The Netherlands). In preparation of the GC-MS analysis, samples were processed to make a trimethylsilyl derivative of lactate, a butylboronic acid acetate derivative of glucose, and a trifluorobutyrate derivative of glycerol. For the preparation of the trimethyl-

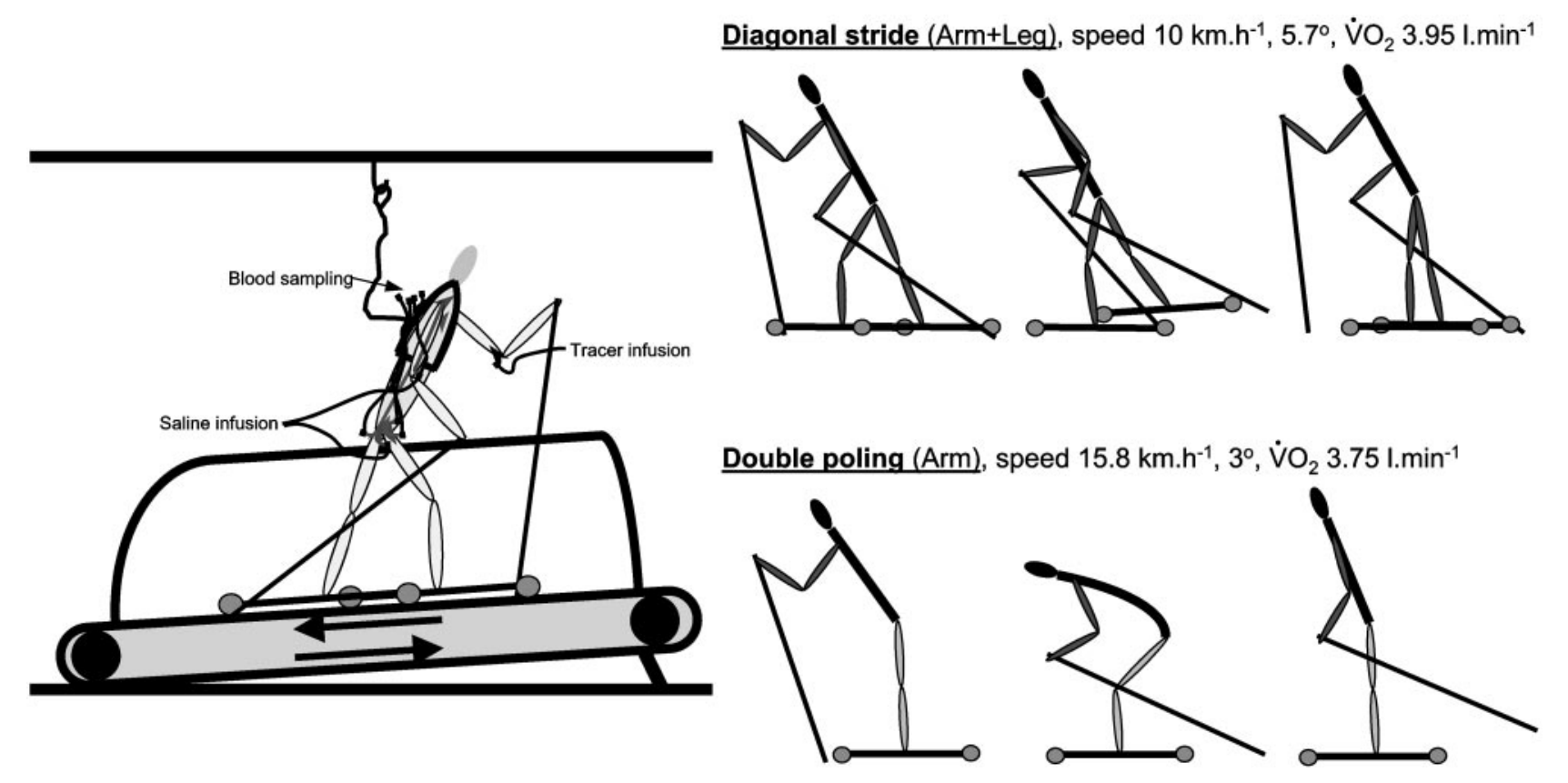

Fig. 2. Design of the experimental setup and description of the skiing modes. 
silyl derivative of lactate, $1 \mathrm{ml}$ of ethanol was added to $200 \mu \mathrm{l}$ of blood extracts and centrifuged for $10 \mathrm{~min}$, and the supernatant was transferred to a new screw-capped tube and evaporated to dryness under a stream of nitrogen. For lactate enrichment, $50 \mu \mathrm{l}$ of pyridine and $50 \mu \mathrm{l}$ of $\mathrm{N}$-( $\mathrm{O}$-bistrimethylsilyl)-trifluoroacetamide, or BSTFA, with $1 \%$ trimethylchlorosilan (or TMCS, Pierce) were added, and the solution was incubated for $30 \mathrm{~min}$ at room temperature. The isotopic enrichment was determined using electron impact ionization, with ions at mass-to-charge ratios $(\mathrm{m} / \mathrm{z}) 219$ and 220 representing the molecular ions of unlabeled and labeled derivatives, respectively. For determination of glucose enrichment, $250 \mu \mathrm{l}$ of water and $3 \mathrm{ml}$ of chloroform-methanol (2.3:1) were added to $150 \mu \mathrm{l}$ of blood extract, vortex mixed for $10 \mathrm{~min}$, and centrifuged at $4^{\circ} \mathrm{C}$ for $15 \mathrm{~min}$. The upper layer was washed once by adding $1 \mathrm{ml}$ of water ( $\mathrm{pH} 2$, with $\mathrm{HCl}$ ) and $2 \mathrm{ml}$ of chloroform and was centrifuged at $4^{\circ} \mathrm{C}$ for $15 \mathrm{~min}$. The upper layer was then evaporated to dryness, after which $250 \mu \mathrm{l}$ of butylboronic acid $(100 \mathrm{mg} / 10 \mathrm{ml}$ pyridine $)$ were added to the dry residue and incubated for $30 \mathrm{~min}$ at $95^{\circ} \mathrm{C}$. After the addition of $250 \mu \mathrm{l}$ of acetic anhydride and incubation for 90 min at room temperature, the solution was evaporated to dryness and redissolved in $100 \mu \mathrm{l}$ of ethyl acetate. The isotopic enrichment was determined using electron impact ionization and ions at $\mathrm{m} / \mathrm{z} 297$ and 299, representing the molecular ions of unlabeled and labeled glucose derivatives, respectively. For the preparation of the fluorobutyrate derivative of glycerol, $3 \mathrm{ml}$ of ethanol-chloroform (2.3:1) were added to $200 \mu$ l of plasma, mixed, and centrifuged. The top layer was extracted once more with $2 \mathrm{ml}$ of chloroform and 1 $\mathrm{ml}$ of water ( $\mathrm{pH} 2$, with $\mathrm{HCl}$ ), mixed, and centrifuged. The top layer was evaporated under a stream of $\mathrm{N}_{2}$. Two hundred microliters of heptafluorobutyric acid anhydride in ethyl acetate $(1: 3, \mathrm{vol} / \mathrm{vol})$ were added to the residue and heated for $10 \mathrm{~min}$ at $70^{\circ} \mathrm{C}$. The solution was evaporated under a stream of $\mathrm{N}_{2}$ and the residue redissolved in $1 \mathrm{ml}$ of ethyl acetate. The isotopic enrichment of glycerol was determined by electron impact ionization, and selective monitoring of ions at $\mathrm{m} / \mathrm{z}$ 252-256, representing the molecular ions of unlabeled (252) and labeled derivatives (256), respectively, was performed.

Muscle biopsies were analyzed for lactate dehydrogenase (LDH), citrate synthase (CS), 3-hydroxyacyl-CoA dehydrogenase (HAD) activity, and LDH isoforms.

\section{Calculations}

The whole body rates of appearance $\left(R_{\mathrm{a}}\right)$ and disappearance $\left(R_{d}\right)$ of lactate, glucose, and glycerol at rest and during exercise were calculated using the steady-state equation

$$
\mathrm{R}_{\mathrm{a}}=\mathrm{R}_{\mathrm{d}}=\mathrm{F} / \mathrm{E}_{\mathrm{a}}
$$

Limb tracer measurements were calculated as

$$
\text { net limb balance }=\left(\mathrm{C}_{\mathrm{a}}-\mathrm{C}_{\mathrm{v}}\right) \times \text { blood flow }
$$

limb fractional extraction $\left.=\left[\left(\mathrm{C}_{\mathrm{a}} \times \mathrm{E}_{\mathrm{a}}\right)-\left(\mathrm{C}_{\mathrm{v}} \times \mathrm{E}_{\mathrm{v}}\right)\right] /\left(\mathrm{C}_{\mathrm{a}} \times \mathrm{E}_{\mathrm{a}}\right)\right]$

limb lactate uptake $=\operatorname{limb}$ fractional extraction $\times \mathrm{C}_{\mathrm{a}}$ $\times$ blood flow

limb lactate release $=$ limb lactate uptake

- net limb balance

$\mathrm{F}$ is the isotopic infusion rate $(\mu \mathrm{mol} / \mathrm{min}), \mathrm{C}_{\mathrm{a}}$ and $\mathrm{C}_{\mathrm{v}}$ and $\mathrm{E}_{\mathrm{a}}$ and $\mathrm{E}_{\mathrm{v}}$ are the arterial and venous concentrations and isotopic enrichments, respectively, in the tracer/tracee ratio.

The blood flow was used to calculate net leg uptake of lactate and glucose. The plasma flow, being blood flow $\times$
(1 - hematocrit), was used to calculate net fatty acid uptake.

Whole body and tissue steady state is a requirement for reliable quantitative tracer estimates of whole body metabolite turnover rates, as well as limb balances of tracers and concentrations, usually referred to as Fick's principle. Complete steady state is difficult to achieve during exercise; however, the lactate and glucose enrichments and concentrations (see Figs. 3 and 7) were similar after 12, 24, and $36 \mathrm{~min}$ of Continuous Arm + Leg, suggesting a reasonable steady state. This was clearly not the case for lactate during the 10 min of Arm and Arm + Leg skiing. However, the lactate turnover rate is high, and it seems reasonable to assume that a near steady state was achieved after $7 \mathrm{~min}$, when the blood sample was obtained. The whole body lactate $R_{d}$ oxidized to $\mathrm{CO}_{2}$ and the limb lactate uptake oxidized to $\mathrm{CO}_{2}$ were markedly lower during Arm and Arm + Leg (see Fig. 5); this might be caused by non-steady-state conditions, most likely in the bicarbonate pool turnover rate and size, since they are known to be affected by changes in $\mathrm{pH}$ and metabolic rate (32). Thus the changes of the bicarbonate pool turnover rate and size resulting in ${ }^{13} \mathrm{CO}_{2}$ output during the Arm and Arm + Leg are potentially not entirely related to lactate oxidation.

\section{Statistical Analysis}

All data are expressed as means \pm SE for six subjects. The nonparametric Wilcoxon signed-rank test was applied to determine differences between leg and arm. Statistical significance was set at $P<0.05$.

\section{RESULTS}

\section{Subject characteristics}

The Swedish elite cross-country skiers had a $\dot{\mathrm{V}}_{2}$ max of $5.2(4.9-5.8) \mathrm{l} / \mathrm{min}$ or $71(65-74) \mathrm{ml} \cdot \mathrm{kg}$ body $\mathrm{wt}^{-1}$. $\min ^{-1}$, assessed during incremental diagonal stride roller skiing. Oxygen uptake $\left(\dot{\mathrm{V}}_{2}\right)$ during the $40 \mathrm{~min}$ of Continuous Arm + Leg and Arm + Leg skiing was $3.95 \pm$ $0.02 \mathrm{l} / \mathrm{min}$ or $76 \pm 1 \% \dot{\mathrm{V}}_{2}$ max. $\dot{\mathrm{V}}_{2}$ during Arm was $3.75 \pm 0.18 \mathrm{l} / \mathrm{min}$ or $72 \pm 2 \% \mathrm{~V}_{2} \max$.

\section{Whole Body and Limb Lactate Kinetics}

Rest and Continuous Arm + Leg. The arterial lactate concentration increased from $0.7 \mathrm{mmol} / \mathrm{l}$ at rest to $\sim 2.5$ $\mathrm{mmol} / \mathrm{l}$ with Continuous Arm + Leg skiing at $76 \%$ $\dot{\mathrm{V}}_{2}$ max and remained nearly constant over the $40 \mathrm{~min}$ (Fig. 3A). Also, whole body lactate $\mathrm{R}_{\mathrm{a} / \mathrm{d}}$ increased during change from rest to exercise (Fig. $3 B$ ); however, the arterial lactate concentration increased only $\sim 3.5$-fold, whereas lactate $R_{\mathrm{a}}$ increased $\sim 10$-fold. At rest, a small limb net lactate release was observed (Fig. 4A). During Continuous Arm + Leg, a constant net lactate release of $\sim 2 \mathrm{mmol} / \mathrm{min}$ by the arm was observed, and in contrast, a net lactate uptake was observed of a similar magnitude and release for the leg. The tracer-estimated limb lactate uptake and release showed a simultaneous uptake for both limbs (Fig. 4, $B$ and $C$ ). The leg lactate uptake was markedly higher, and the lactate release was similar, for leg and arm. However, to compare leg and lactate kinetics, the difference in skeletal muscle mass has to be taken into account. When lactate uptake and release are expressed per kilogram of skeletal muscle, the picture is reversed 

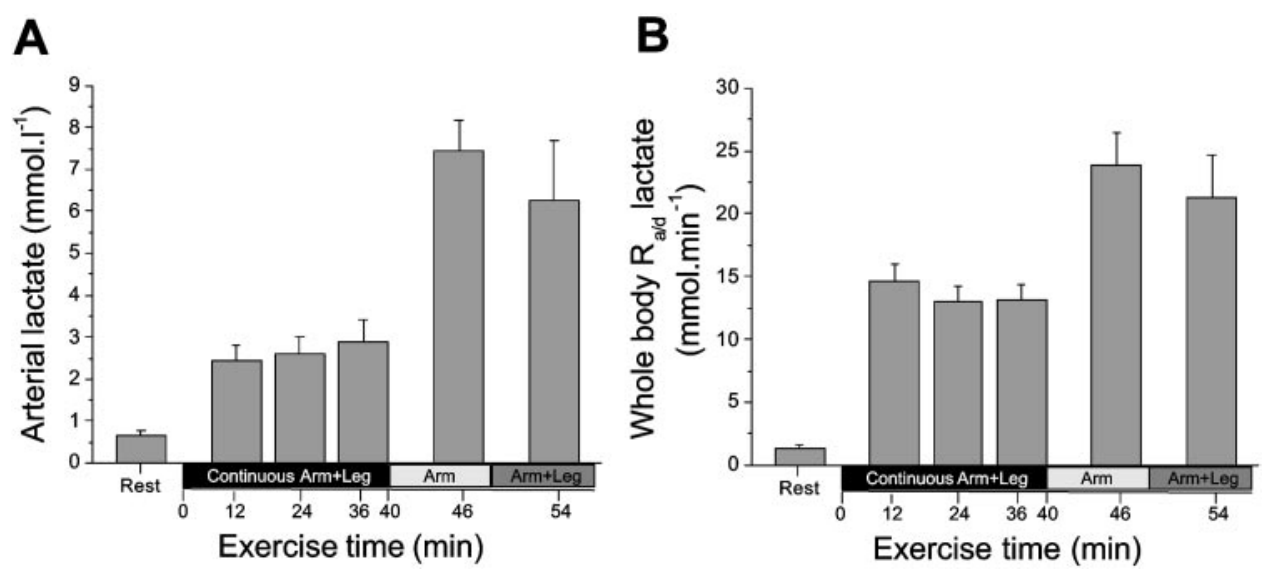

Fig. 3. Whole body lactate concentration $(A)$ and rates of appearance and disappearance $\left(\mathrm{R}_{\mathrm{a} / \mathrm{d}}, B\right)$. Values are means \pm SE of 6 subjects.
(Fig. 4, $D$ and $E$ ). The leg and arm lactate uptake values are rather similar, but lactate release is substantially higher for the arm. Thus the difference in the leg and arm net lactate exchange, in which the leg is a net lactate consumer and the arm a net lactate producer, seems to be caused solely by the difference in magnitude of lactate release. At rest, the $42-55 \%$ of the lactate leaving the circulation and taken up by the limb was found oxidized, and during Continuous Arm + Leg nearly all was oxidized (Fig. 5). When limb lactate uptake and release were plotted as a function of limb lactate delivery (arterial lactate concentration times limb blood flow), a tight correlation was observed between limb lactate delivery and limb uptake, and not limb release (Fig. 6).

Arm and Arm + Leg. Within 7 min of Arm skiing, the arterial lactate concentration increased more than threefold. A substantial decrease in the lactate concentration could be observed after the 10 min of Arm + Leg skiing at the same intensity as the $40 \mathrm{~min}$ of Continuous Arm + Leg before the Arm skiing. The pattern of changes in lactate $R_{a}$ imaged the changes observed for the arterial lactate concentration, even though the relative changes were quantitatively rather different. When going from the 40 min of Continuous Arm + Leg to Arm skiing, the arterial lactate concentration increased 2.5-fold within $5 \mathrm{~min}$, whereas lactate $R_{a}$ increased only 0.7 -fold. The leg net lactate uptake and arm net lactate release values were exaggerated during Arm exercise. The increase in leg net lactate uptake was caused by an increased lactate uptake and a decreased leg lactate release, whereas the increase in arm net lactate release was due to an increase in both lactate uptake and release, even though the latter increased more. During the 10 min of Arm + Leg skiing following Arm skiing, a limb net lactate exchange could not be observed. In the case of the leg, the net lactate uptake was minimized because of a substantial increased lactate release that was far higher then the increase in lactate uptake. In the case of the arm, the net lactate uptake was minimized because of a decrease in lactate release and an increase in lactate uptake.

\section{Whole Body and Limb Carbohydrate and Fat Utilization}

Rest and Continuous Arm + Leg. At rest, whole body respiratory exchange ratio (RER) and limb respiratory quotient (RQ) were rather similar. However, it is clear that the contribution of the limbs to energy expenditure, and thus RER, is relatively small at rest $(\sim 40 \%)$ compared with exercise $(\sim 80 \%)$. The relative contribution of lactate oxidation to total carbohydrate utilization was $\sim 30 \%$ for the whole body and $20 \%$ for the limbs. The rate of leg net fatty acid uptake was similar to total leg fat utilization. This calculation could not be made for the arm, since the positioning of the subclavian venous catheter did not exclude contamination by subcutaneous adipose tissue and skin. During Continuous Arm + Leg, whole body and limb total carbohydrates and fat utilization were rather similar over time (Table 1). However, during Continuous Arm + Leg, the whole body glucose $\mathrm{R}_{\mathrm{a} / \mathrm{d}}$, and especially leg net glucose uptake, increased with exercise duration (Fig. 7, B and $C$ ), whereas the leg net fatty acid uptake did not change (Fig. 8D). This suggests that the leg muscle glycogen utilization decreased with exercise duration. The relative contribution of lactate oxidation to carbohydrate utilization was rather similar for the whole body (28\%), legs (35\%), and arms (27\%) (Fig. 9).

Arm and Arm + Leg. The RER increased during Arm skiing but returned during Arm + Leg to levels similar to those observed during Continuous Arm + Leg (Table 1). This indicates that Arm skiing elicited an increase in carbohydrate utilization. Despite considerable variability in limb RQ, the enhanced RER during Arm skiing is caused by enhanced arm carbohydrate utilization. Blood glucose was the main carbohydrate source for the arm during Arm, whereas the contribution of lactate oxidation was unchanged. In contrast, leg RQ decreased and net glucose uptake diminished during Arm compared with Continuous Arm + Leg. Thus the lowering of "work" by the legs elicited an enhanced reliance on fat. Because the leg net fatty acid uptake was similar during Arm and Continuous Arm + Leg, the contri- 
Fig. 4. Limb lactate kinetics. Limb net lactate exchange $(A)$ is arteriovenous concentration times blood flow. Limb lactate uptake $(B)$ is tracer-calculated lactate uptake, and limb lactate release $(C)$ is tracer-calculated limb lactate uptake minus net limb lactate exchange. $D$ and $E$ : limb lactate uptake and release, respectively, expressed per kilogram of skeletal muscle. Estimations are based on the assumption that muscle mass of the leg ranges between 8 and $10 \mathrm{~kg}$ and that the upper body muscle mass of the arm ranges between 3 and $4 \mathrm{~kg}$. Solid parts of bars represent estimates with the low muscle mass, and gray parts of bars represent estimates with the highest muscle mass. Values are means $\pm \mathrm{SE}$ of 6 subjects. * Not significantly different from zero; " significantly different from leg.

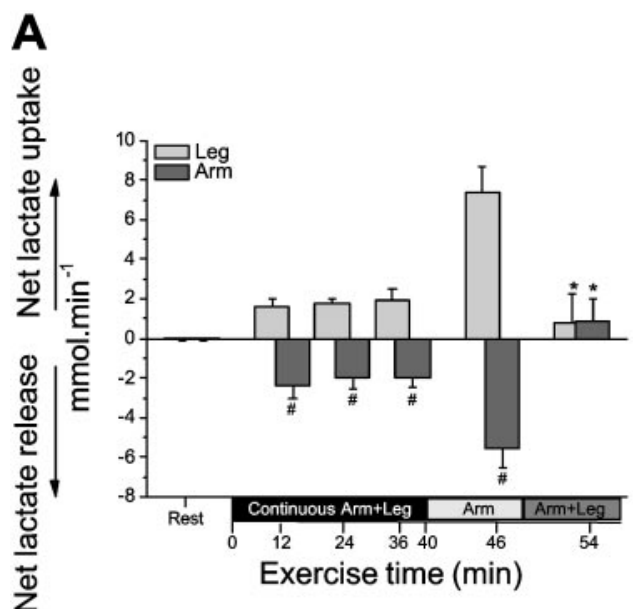

B

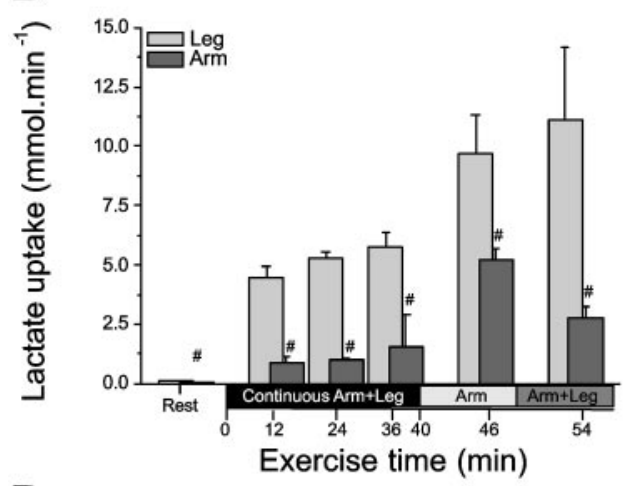

D

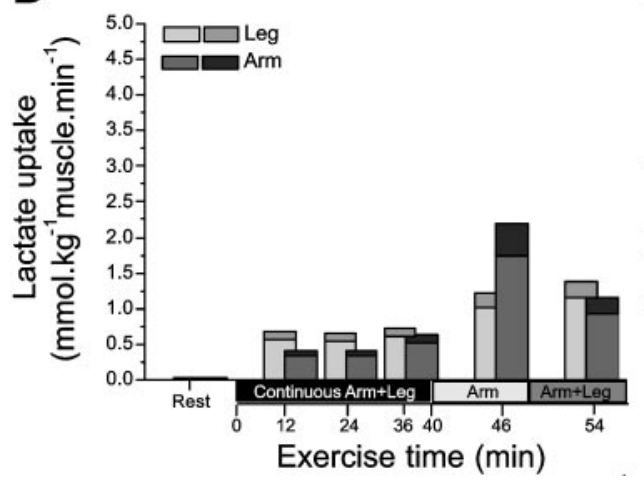

C

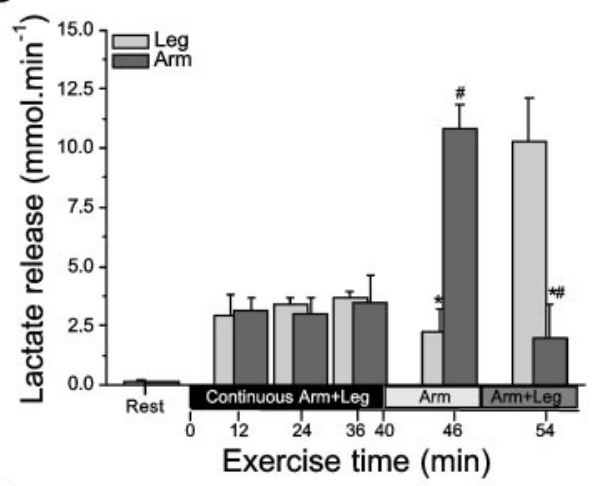

E

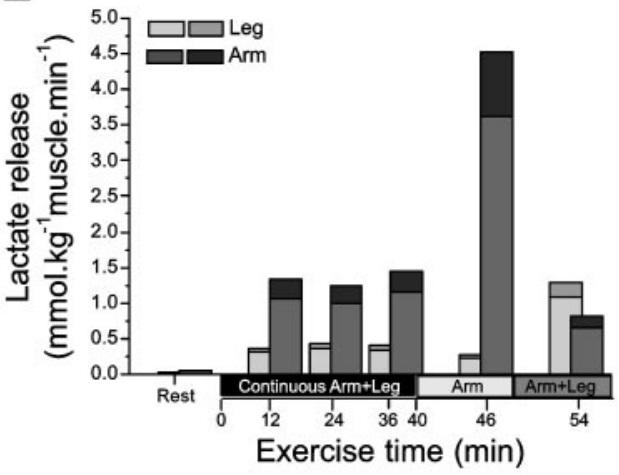

bution of muscle triacylglycerol must have increased. The main differences observed during Arm + Leg compared with Continuous Arm + Leg were the higher arm lactate uptake and net glucose uptake. These were most likely caused by the previous exercise, resulting in a substantial reduction in muscle glycogen, hence reduced utilization.

\section{Catecholamines}

Arterial epinephrine and norepinephrine concentrations increased from rest to exercise but remained unchanged during all skiing modes. The arterial epinephrine concentration was $1-1.2 \mathrm{nmol} / \mathrm{l}$, and norepinephrine was $10-12 \mathrm{nmol} / \mathrm{l}$.

\section{Skeletal Muscle LDH Activity and Isoforms, and $C S$ and $H A D$ Activities}

Muscle biopsies were obtained from the vastus lateralis of seven skiers. The LDH activity was low (Fig. 10), with a very high contribution of the hearttype LDH isoform (H-LDH, 70\% of the total LDH). The LDH-2 type is the most predominant isoform, and only $6 \%$ consisted of the pure muscle type LDH (M-LDH), the LDH-5. In the three skiers from whom biopsies of both muscles were obtained, the vastus lateralis $\mathrm{LDH}$ activity was nearly one-half that of the deltoid; however, the contribution of the LDH isoforms was almost identical in both muscles. The activity of the oxidative enzymes CS and HAD was 
A

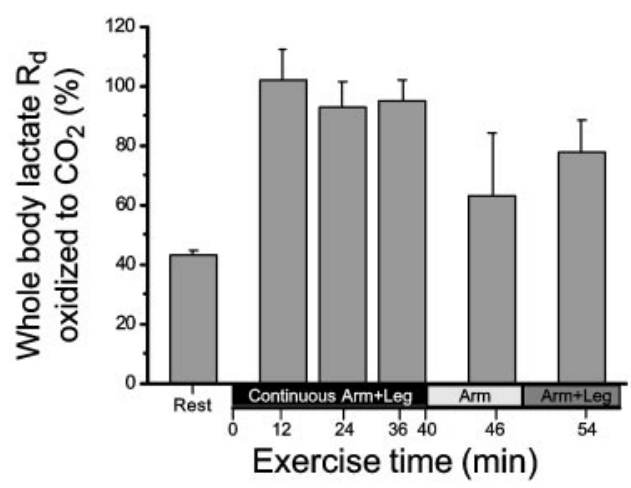

B

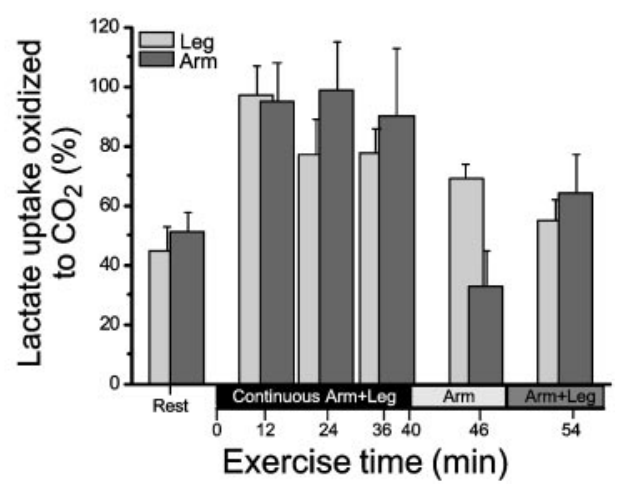

Fig. 5. Whole body and limb lactate oxidation. Whole body lactate oxidation is estimated as the whole body lactate rate of disappearance $\left(\mathrm{R}_{\mathrm{d}}\right)$ recovered in breath $\mathrm{CO}_{2}(A)$; limb lactate oxidation is estimated as the tracer lactate uptake (see Fig. $4 B$ ) recovered in blood $\mathrm{CO}_{2}(B)$. Values are means \pm $\mathrm{SE}$ of 6 subjects. lower in the vastus lateralis than in the deltoid (Table 2).

\section{DISCUSSION}

There are four main findings of the present study. 1) The arterial lactate concentration can be maintained at a relatively low level despite a high lactate $R_{\mathrm{a}}$ during exercise with a large muscle mass because of the large capacity of active skeletal muscle to take up lactate. 2) Leg lactate uptake is tightly correlated with lactate delivery. However, the limb lactate uptake during exercise is oxidized at rates far above resting $\mathrm{V}_{2}$, implying that lactate uptake and subsequent oxidation are also dependent on an elevated metabolic rate. 3) The contribution of whole body and limb lactate oxidation was between 20 and $30 \%$ of total carbohydrate oxidation at rest and during exercise. 4) Skeletal muscle can change its glucose uptake severalfold within minutes, causing a redistribution of the available glucose when whole body glucose turnover is unchanged.

At rest, the systemic lactate $R_{\mathrm{a}}$ of the athletes $(18 \pm$ $3 \mu \mathrm{mol} \cdot \mathrm{kg}$ body $\operatorname{mass}^{-1} \cdot \mathrm{min}^{-1}$ ) was rather similar to the $R_{a}$ observed in active young subjects $(17 \pm 2$ $\mu \mathrm{mol} \cdot \mathrm{kg}$ body $\left.\operatorname{mass}^{-1} \cdot \min ^{-1}\right)$, and so was the relative contribution of leg lactate release to systemic lactate $R_{\mathrm{a}}(34)$. This suggests that no difference exists between highly trained and active young individuals in whole body and skeletal muscle lactate appearance and clearance at rest. The $40 \mathrm{~min}$ of Continuous Arm + Leg exercise was performed at a high relative intensity $\left(76 \% \dot{\mathrm{V}}_{2}\right.$ max $)$. Despite this high work intensity, the arterial lactate concentration was only moderately increased. It could have been anticipated that these athletes would produce a small amount of lactate compared with less-trained individuals. However, the arterial lactate concentration is not a good indicator of lactate production during exercise. During the $40 \mathrm{~min}$ of Continuous Arm + Leg, the lactate $R_{a}$ was $184 \pm 17$ $\mu \mathrm{mol} \cdot \mathrm{kg}$ body mass ${ }^{-1} \cdot \mathrm{min}^{-1}$. During bicycle exercise in active subjects, we have observed an arterial lactate concentration of $1.8 \mathrm{mmol} / \mathrm{l}$ at $46 \% \dot{\mathrm{V}}_{2}$ max, with a lactate $R_{\mathrm{a}}$ of $\sim 60 \mu \mathrm{mol} \cdot \mathrm{kg}$ body $\mathrm{mass}^{-1} \cdot \mathrm{min}^{-1}$, and an arterial lactate concentration of $\sim 6 \mathrm{mmol} / \mathrm{l}$ at $82 \%$ $\dot{\mathrm{V}}_{2}$ max with a lactate $R_{\mathrm{a}}$ of $160 \mu \mathrm{mol} \cdot \mathrm{kg}$ body $\operatorname{mass}^{-1} \cdot \min ^{-1}(34)$. The latter lactate $R_{a}$ is thus even lower than during the 40 min of Continuous Arm + Leg. This is the case despite a 2.5-fold difference in the arterial concentration. It is clear that the higher lactate uptake compared with lactate release of the legs is the reason for a low lactate concentration despite a high lactate turnover rate. It has been shown that, in recovery from exercise, the lactate concentration decreases faster when exercise is performed $(14,24)$. In addition, when lactate was infused at the same rate at rest and during exercise at different intensities, the increase in lactate concentration became lower the higher the exercise intensity (27). These studies indicated that active skeletal muscle is an important consumer of lactate, not only a producer of lactate, despite a net lactate release, as shown previously $(15,16,31)$.
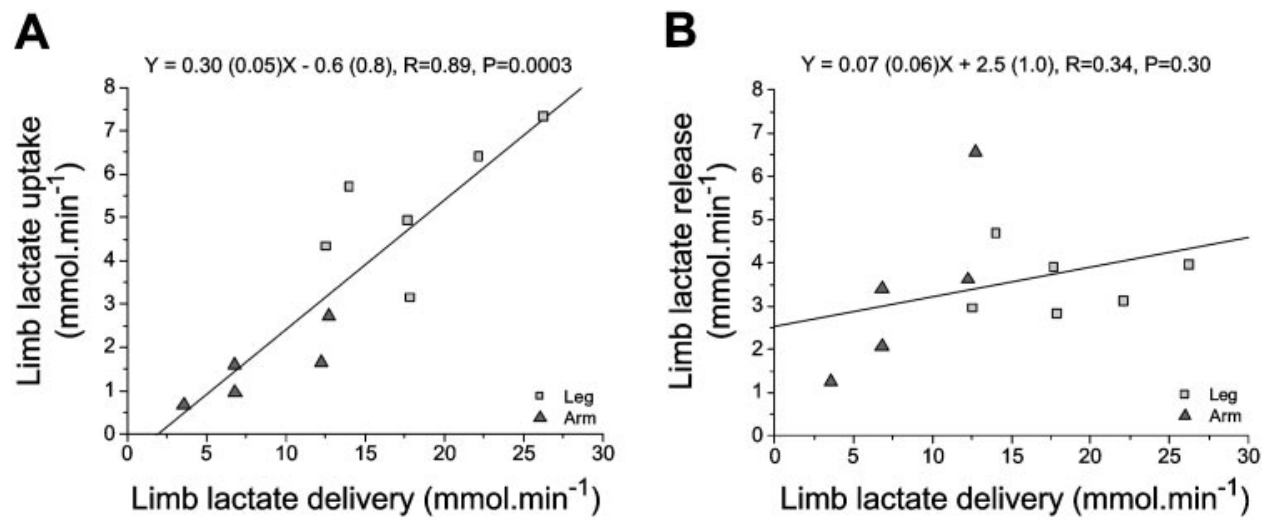

Fig. 6. Correlation of limb lactate delivery with limb lactate uptake $(A)$ and limb lactate release $(B)$. Data points are averages for each individual of 3 measurements during $40 \mathrm{~min}$ of continuous Arm + Leg skiing of leg $(n=6)$ and $\operatorname{arm}(n=5)$ lactate delivery vs. lactate uptake or release. Limb lactate delivery is arterial concentration times limb blood flow. 
Table 1. Parameters of systemic and limb oxygen uptake and energy utilization

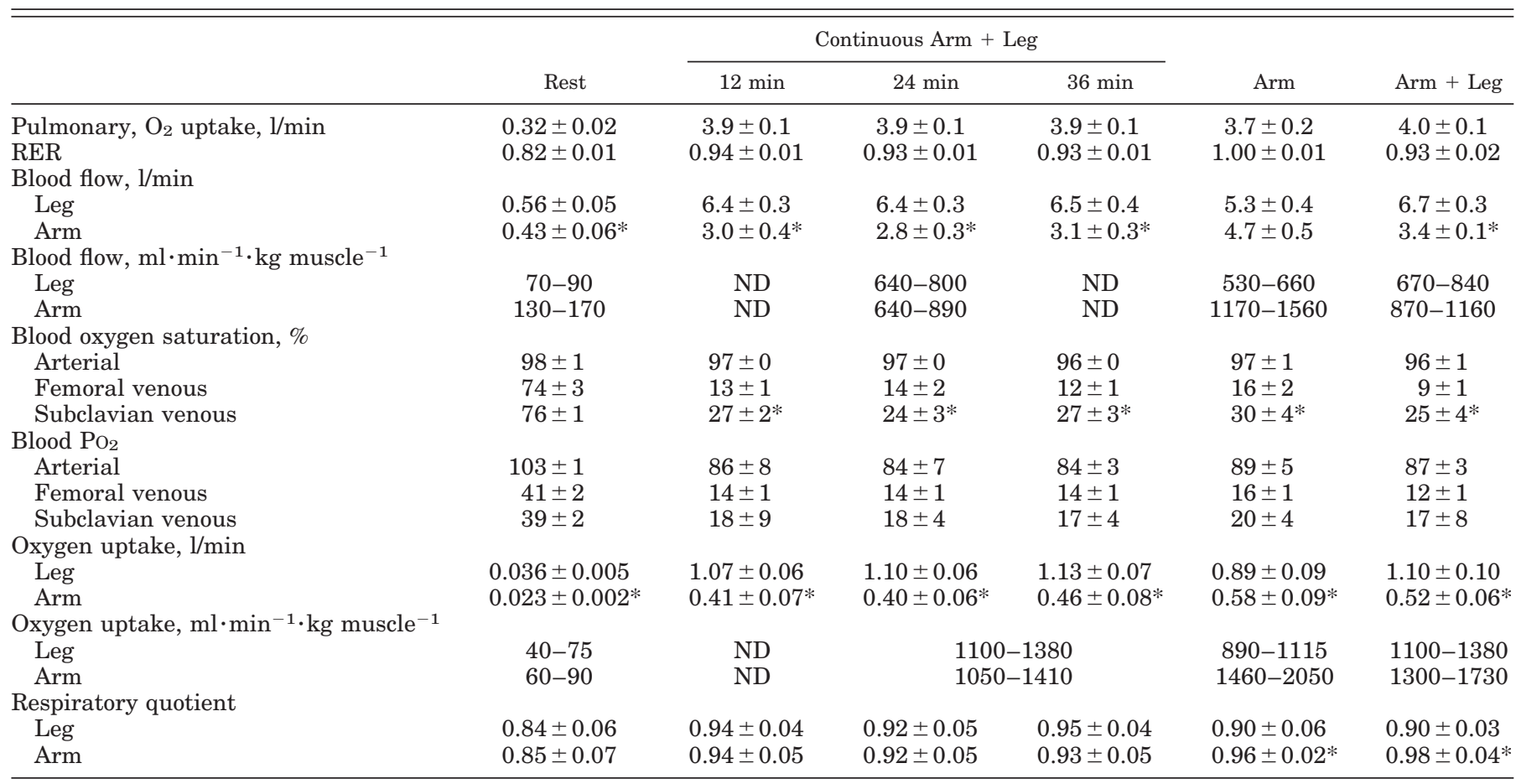

Values are means $\pm \mathrm{SE}$ of 6 subjects or ranges based on estimates of lowest to highest limb muscle mass. Estimates of limb blood flow and oxygen uptake per kilogram of skeletal muscle are based on a leg muscle mass ranging from 8 and $10 \mathrm{~kg}$, and that of the arm (upper body) from 3 and $4 \mathrm{~kg}$. RER, respiratory exchange ratio; ND, not determined because of large variability in blood $\mathrm{CO}_{2}$ content. $*$ Significantly different from leg or femoral vein.

The current study shows not only that skeletal muscle is the most important tissue for lactate clearance during exercise but also that active skeletal muscle can be a substantial net lactate consumer. In fact, if inactive leg skeletal muscle had to take up and oxidize the amounts of lactate observed during exercise in the present study, it would require an oxygen utilization about fourfold higher than that actually observed for the resting leg. This implies that only active skeletal muscle, due to its multiple times of increased energy expenditure, and not resting skeletal muscle, is able to oxidize the large amounts of lactate produced during exercise.

The elite cross-country skiers in the present study have well-trained leg and arm muscles, which makes them suitable in the comparison of metabolic properties of leg and arm skeletal muscle without having to take the confounding effect of more trained leg than arm muscles into consideration. However, to compare leg and arm muscles, the energy turnover of both the legs and the arms has to be known. The legs contain more muscle than arms. Thus the data have to be expressed per kilogram of muscle or, more specifically, the muscle mass over which the arteriovenous difference for lactate is measured needs to be known. Leg muscle mass is $8-10 \mathrm{~kg}$, and arm muscle mass is $3-4$ $\mathrm{kg}$ in young trained subjects. We have used this range of muscle mass to express leg and arm data per kilogram of muscle (Table 1, Figs. 4 and 7). If blood flow to and $\dot{\mathrm{V}}_{2}$ by the limbs were expressed per kilogram of limb muscle, then leg and arm blood flow and oxygen utilization would be similar during Continuous Arm + Leg. This indicates that, during Continuous Arm + Leg, the leg and arm muscles performed a similar absolute amount of work per kilogram of muscle. In addition, during Continuous Arm + Leg, the leg and arm net glucose uptake values were similar. Despite similar work and net glucose uptake, the leg lactate uptake was higher and the leg lactate release lower than for the arm (Fig. 4). This would suggest that the arm muscles have a lower ability to utilize lactate and a higher ability to produce lactate when moderately to highly active. However, although the data may suggest a similar amount of work by legs and arms, they do not provide information as to whether the relative workloads were similar. Arterial lactate and net lactate release across an exercising limb strongly correlate with relative workload. The athletes indicated that the work performed by the arms during Arm skiing was close to what they could maximally do with their arms. This would mean that the relative arm intensity during continuous Arm + Leg was $\sim 60 \%$ of maximal arm $\dot{\mathrm{V}}_{2}$ and thus higher than the relative intensity by the legs, which was estimated to be $\sim 45 \%$. On the other hand, this would imply that arm muscles could do less work than leg muscles per kilogram of skeletal muscle. It is of note that, when maximal leg exercise with a large muscle mass (bicycle exercise) is compared with leg exercise with a small muscle mass (one-leg kneeextensor exercise), work performed and $\dot{\mathrm{V}}_{2}$ per kilo- 

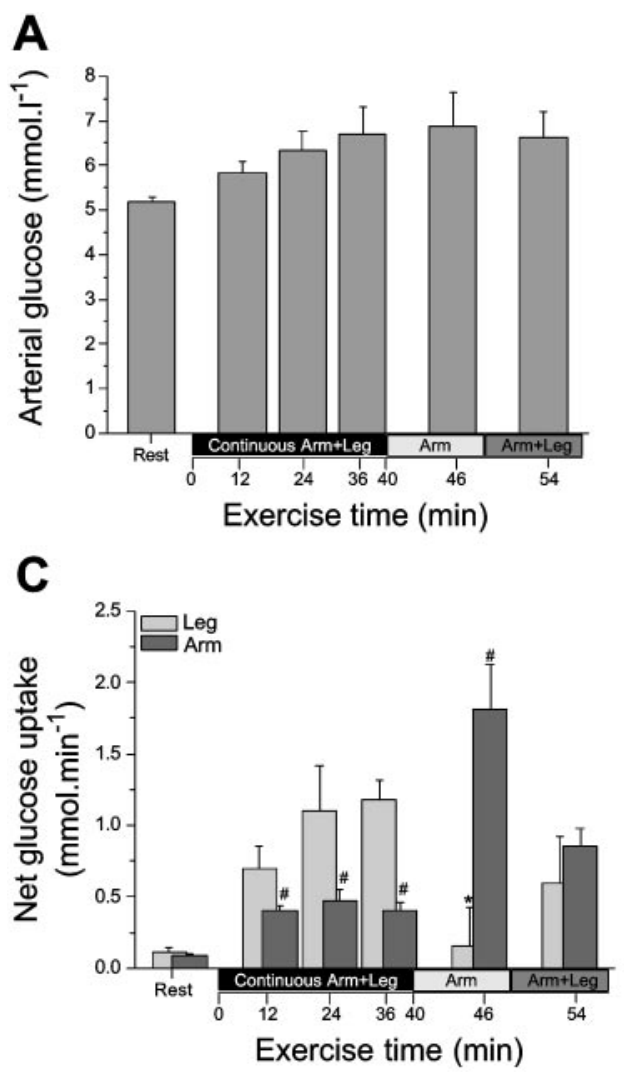

B

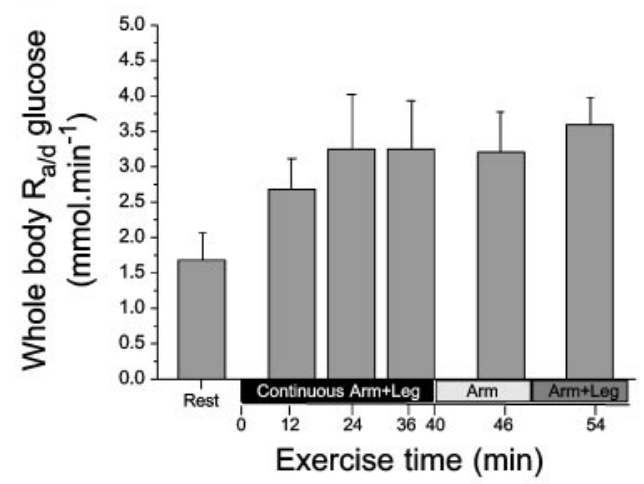

D

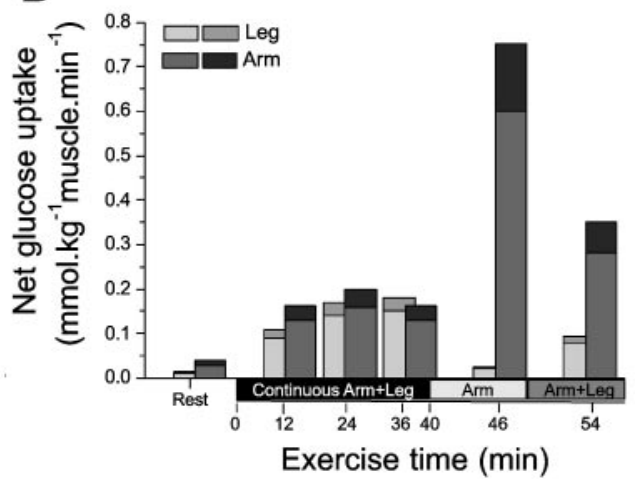

Fig. 7. Whole body and limb glucose kinetics. $A$ : arterial glucose concentration; $B$ : whole body glucose rates of appearance and disappearance; $C$ : limb net glucose uptake presented as the arteriovenous concentration times blood flow; $D$ : limb net glucose uptake expressed per $\mathrm{kg}$ of skeletal muscle. Estimations are based on the assumption that the muscle mass of the leg ranges between 8 and $10 \mathrm{~kg}$ and the upper body muscle mass of the arm ranges between 3 and $4 \mathrm{~kg}$. In $D$, solid part of bars represents estimates with low muscle mass, and gray part of bars represents estimates with the highest muscle mass. Values are means $\pm \mathrm{SE}$ of 6 subjects. * Not significantly different from zero; " significantly different from leg.
Fig. 8. Whole body glycerol kinetics, fatty acid (FA) concentration, and limb net exchange. $A$ : arterial concentration of glycerol; $B$ : rate of appearance of glycerol as an indicator of whole body lipolysis; $C$ : arterial concentration of fatty acids; $D$ : limb net fatty acid uptake. Values are means \pm SE of 6 subjects. * Not significantly different from zero; "significantly different from leg.
A

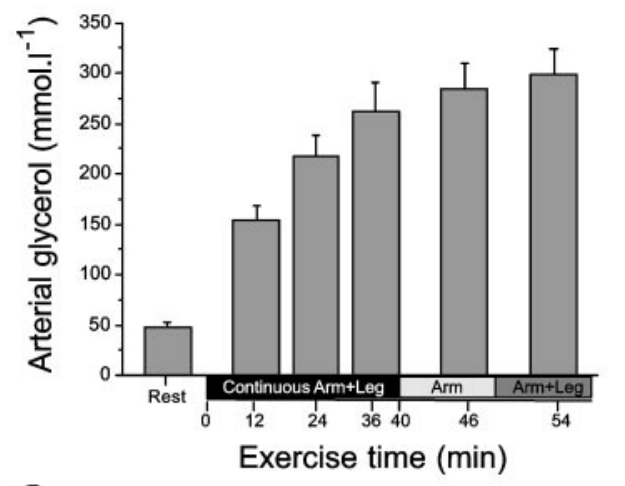

C

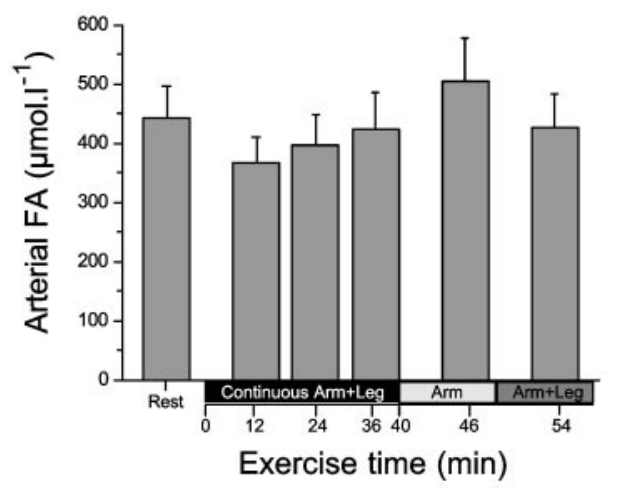

B

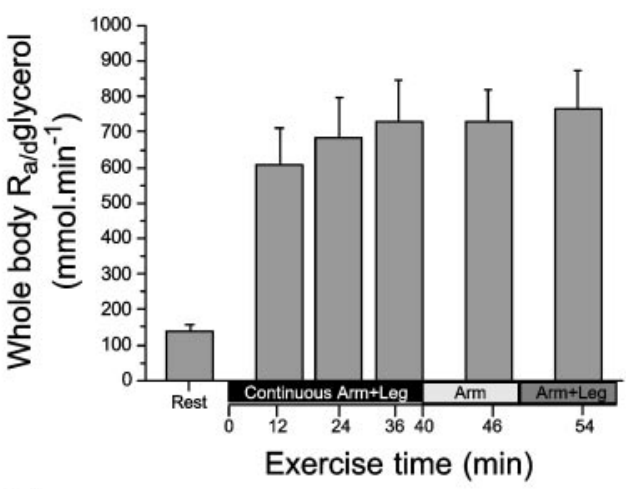

D

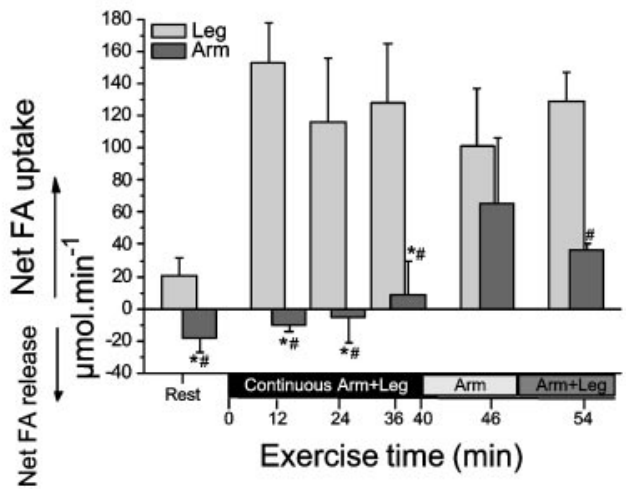


Fig. 9. Whole body and limb carbohydrate and fat utilization. Values show absolute and relative whole body and limb carbohydrate $(A)$ and fat $(B)$ utilization at rest and the average utilization during continuous Arm + Leg $(C$ and $D$ ). Contributions of fatty acid (FA) to total fat utilization and of net glucose uptake to total carbohydrate utilization are estimated with the assumption that limb net FA uptake is completely oxidized. The contribution of glycogen is the limb carbohydrate oxidation - net glucose uptake - lactate oxidation.

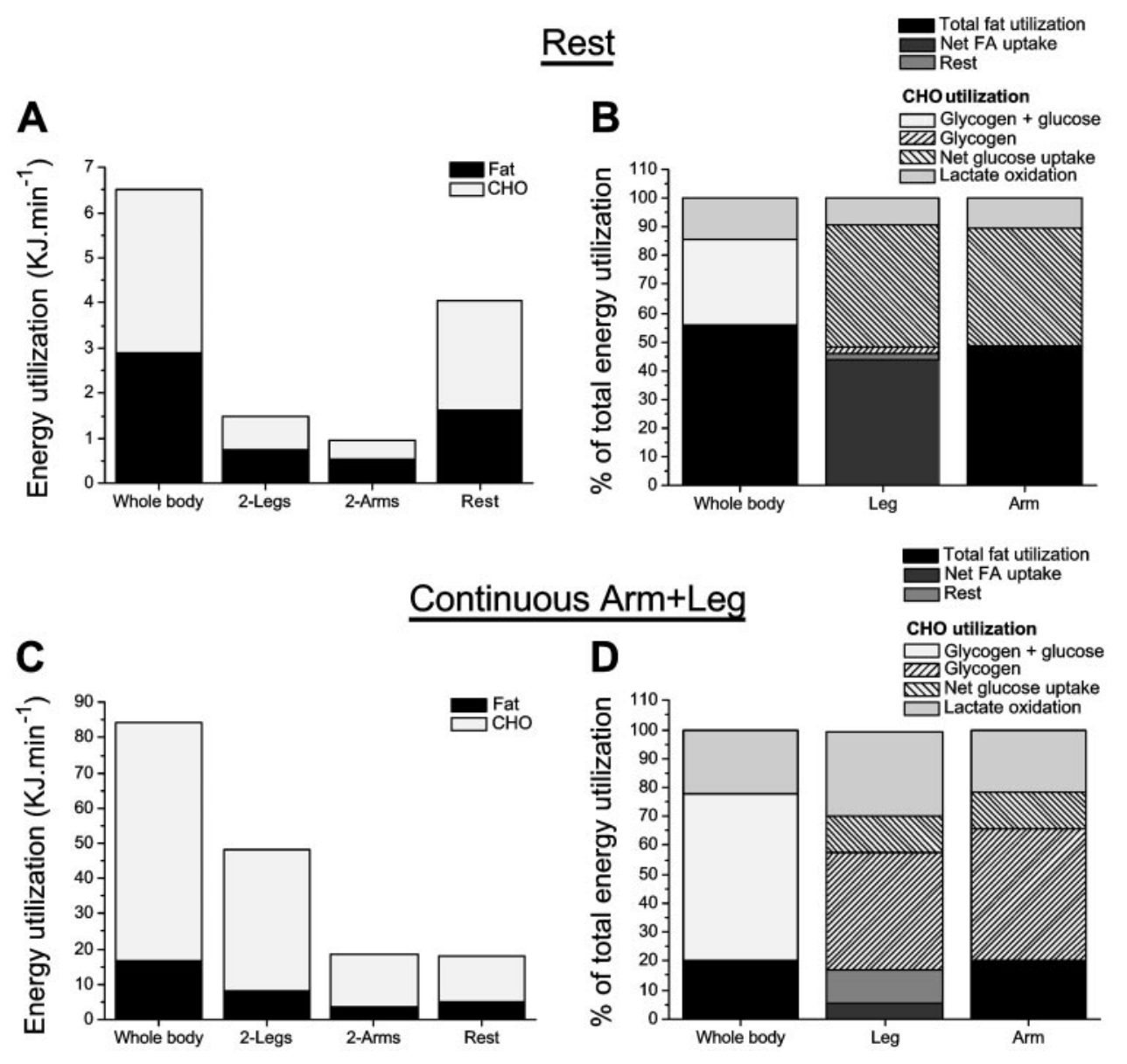

gram of muscle are about twofold higher during exercise with the small muscle mass (35). Alternatively, the lower lactate utilization and higher production of the arm vs. the leg muscle might be explained by differences in arm and leg muscle fiber type and LDH isoform composition. Mygind (22) reported a fairly small difference in slow-twitch fiber content in vastus lateralis $(69 \%)$ and triceps brachii $(51 \%)$ of elite crosscountry skiers. The lower LDH activity in the vastus lateralis compared with deltoid in the present study also seems to suggest a markedly higher slow-twitch fiber content in leg compared with arm muscles. However, the high and similar H-LDH isoform contribution to total LDH actually suggests a similar metabolic profile in legs and arms of the present subjects. Skeletal muscle H-LDH has been considered to catalyze the reaction of lactate to pyruvate, whereas the muscletype LDH (M-LDH) catalyzes pyruvate to lactate (9). However, the role of H-LDH and M-LDH in muscle lactate utilization or production has been questioned (33). It has been suggested that all LDH isoforms are equally able to utilize and produce lactate; this is supported by the observation in LDH M-subunit-deficient patients that muscle lactate production is proportional to total LDH activity compared with healthy controls after ischemic work (17).

Lactate is simultaneously taken up and released by skeletal muscle. A variety of explanations could ac- count for this observation. It has been suggested that, because of the rapid equilibrium between lactate and pyruvate, the release of unlabeled lactate is a result of simple isotopic exchange by $\mathrm{LDH}(18,19,36)$. If isotopic exchange equilibrium were the sole mechanism leading to unlabeled lactate formation, the muscle enrichment of lactate and pyruvate would be similar. However, it has been shown that pyruvate enrichment in skeletal muscle is substantially lower than lactate (Refs. 8 and 20, and van Hall, unpublished observations). More importantly, if the lactate release were to be explained by a rapid isotopic exchange, then the lactate tracer would provide a measure for pyruvate flux. Thus the lactate oxidation would have provided an estimate of pyruvate oxidation, which is entirely carbohydrate oxidation. However, in the present study, it is clearly demonstrated that whole body and limb lactate oxidation is between 20 and $30 \%$ of carbohydrate oxidation under the various conditions (for a detailed discussion see Ref. 21). In addition, the tight correlation between lactate uptake and lactate delivery but not between lactate delivery and lactate release suggests that the pathways of lactate release in muscle are separate and regulated independently. Another explanation is muscle fiber heterogeneity, with lactate production (release) occurring in fast-glycolytic (type IIB) fibers and uptake and oxidation in slow-oxidative (type I) fibers (3). This model, however, does not seem 


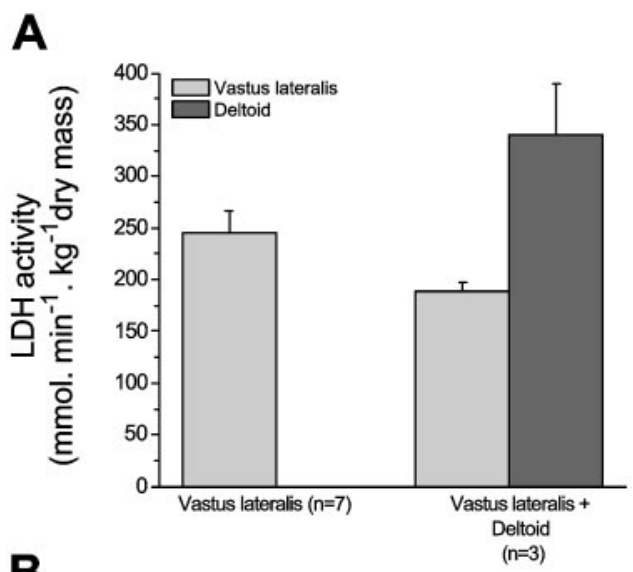

B
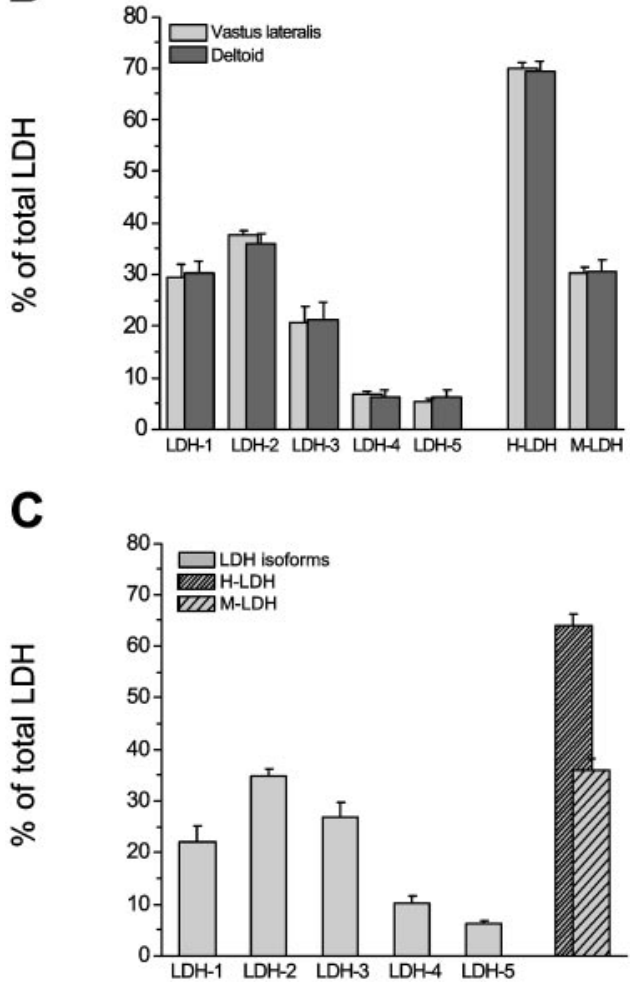

Fig. 10. Skeletal muscle lactate dehydrogenase (LDH) activity and isoform distribution. $A$ : limb $\mathrm{LDH}$ activity is measured in vastus lateralis only $(n=7)$ and in both vastus lateralis and deltoid $(n=3)$. $B$ : $\mathrm{LDH}$ isoform distribution (LDH-1 to -5 ) in vastus lateralis and deltoid $(n=3)$, and total heart-type $(\mathrm{H})$ and muscle-type $(\mathrm{M}) \mathrm{LDH}$ isoforms; H-LDH was calculated as (LDH-1 + $0.75 \mathrm{LDH}-2+0.5$ $\mathrm{LDH}-3+0.25 \mathrm{LDH}-4) /$ total LDH; M-LDH was calculated as (LDH$5+0.75$ LDH-4 + 0.5 LDH-3 + 0.25 LDH-2)/total LDH. C: LDH isoform and total $\mathrm{H}$ - and $\mathrm{M}-\mathrm{LDH}$ distribution in vastus lateralis $(n=7)$.

to be adequate for predicting the simultaneous lactate uptake and release at rest and the tight correlation between lactate uptake and lactate delivery. Furthermore, it implies that the LDH equilibrium in type IIB fibers is toward lactate formation as opposed to pyruvate formation in type I fibers, which is highly unlikely. Thus isotopic exchange and muscle heterogeneity do not seem to explain the simultaneous lactate uptake and release by skeletal muscle, although some contribution cannot be completely excluded. We believe that results of this study are most consistent with the concept of muscle intracellular compartmentation, with at least two functional lactate pools: a myofibrillar pool, to be considered as "glycolytic" and associated with pyruvate derived from blood glucose and glycogen, and an intermyofibrillar pool, to be considered as "oxidative" and associated with extracellular lactate and the pyruvate pool destined for mitochondrial oxidation. This concept is analogous to suggestions for pyruvate compartmentation in skeletal muscle (29) and heart (6, $23)$. Lactate of the glycolytic pool originates mainly from newly synthesized lactate from pyruvate produced from glucose, and during exercise from glucose and glycogen. Lactate formation via $\mathrm{LDH}$ is favored, since both pyruvate and $\mathrm{NADH}$ are relatively high because of glycolysis. Lactate from this pool is the lactate predominantly released from muscle. On the other hand, lactate of the oxidative pool consists mainly of extracellular lactate taken up from the circulation. Lactate from this pool is converted to pyruvate via $\mathrm{LDH}$, because pyruvate may be relatively low and $\mathrm{NAD}^{+}$relatively high in close proximity to the mitochondria. The subsarcolemmal mitochondria may be most involved because of their spatial advantage for this process. Lactate from this pool is the lactate taken up by muscle. No role for mitochondrial LDH is foreseen in this concept, as proposed previously $(4,5)$, because evidence has recently been presented that $\mathrm{LDH}$ is absent in human, mouse (25), and rat (28) skeletal muscle mitochondria. In addition, the $\mathrm{NAD}^{+}$$\mathrm{NADH}$ redox couple is highly reduced. Thus if $\mathrm{LDH}$ were present in the mitochondrial matrix, it would reduce pyruvate to lactate and $\mathrm{NADH}$ would be oxidized, depriving the tricarboxylic acid cycle and the respiratory chain of their main substrates.

The leg net glucose uptake was higher than the arm net glucose uptake during Continuous Arm + Leg, but when expressed per kilogram of muscle, the arm net glucose uptake was similar. However, when work performed by the arms was increased, going from Continuous Arm + Leg to Arm skiing, the skeletal muscle glucose uptake increased severalfold within minutes, and the opposite was true for the legs. These quantitatively large and fast changes in limb net glucose uptake occurred without a change in whole body glucose $R_{d}$, glucose concentration, and catecholamines. The data suggest that the severalfold increase in arm net glucose uptake is mediated by an enhanced interstitial-intracellular glucose gradient caused by an en-

Table 2. Skeletal muscle CS and HAD activity

\begin{tabular}{lcc}
\hline \hline & CS & HAD \\
\hline Vastus lateralis $(n=7)$ & $50 \pm 3$ & $28 \pm 3$ \\
Vastus lateralis $(n=3)$ & $51 \pm 4$ & $28 \pm 3$ \\
Deltoid $(n=3)$ & $38 \pm 4$ & $25 \pm 2$ \\
\hline
\end{tabular}

Values are means $\pm \mathrm{SE}$ expressed in $\mu \mathrm{mol} \cdot \mathrm{min}^{-1} \cdot \mathrm{kg}$ dry mass $^{-1}$. $\mathrm{CS}$, citrate synthase; HAD, 3-hydroxyacyl-CoA dehydrogenase. Vastus lateralis muscle biopsies were obtained from seven skiers; in three of these athletes the enzyme activity in both vastus lateralis and deltoid muscles was measured. 
hanced glucose utilization, since it seems unlikely that the number of sarcolemmal GLUT4 transporters would increase severalfold within minutes. Furthermore, an enhanced glucose delivery does not seem to have an important role, as the increase in blood flow to the arm $(\sim 50 \%)$ was far less than the changes in net glucose uptake. Richter et al. (26) observed that the active leg changed from a net lactate release to an uptake when more limbs became active. In addition, a substantial decrease in the leg net glucose uptake was observed when more limbs became active. However, the combined net lactate and glucose uptake was rather similar. In the present study, leg net glucose uptake was reduced to zero during Arm skiing; however, the combined net lactate and glucose uptake was higher than with Continuous Arm + Leg. Thus lactate should be looked upon as an important carbohydrate source in the blood, next to glucose, since its oxidation contributed $20-30 \%$ of total carbohydrate oxidation at rest and during exercise. This study clearly shows that skeletal muscle has the ability to change rapidly its substrate source when the work performed by the arms and legs changes. There is the possibility that the increase in arm blood lactate and glucose utilization might not be a result of changes in work intensity or availability (lactate) but rather a result of diminished glycogen stores and, hence, reduced contribution of glycogen to carbohydrate oxidation.

The help from the staff and use of the facilities at the Department of Cardiology and Clinical Physiology of the Karolinska Hospital, Sweden, were highly appreciated. We also thank Carsten Juel and Laurant Messonnier for the LDH isoform measurements.

This study was supported by grants from the Swedish Olympic Committee, Team Danmark, and the Sport Research Council of the Ministry of Culture. The Copenhagen Muscle Research Centre is funded by a grant from the Danish National Research Foundation (Grant no. 504-14).

\section{REFERENCES}

1. Ahlborg G, Hagenfeldt L, and Wahren J. Substrate utilization by the inactive leg during one-leg or arm exercise. $J$ Appl Physiol 39: 718-723, 1975.

2. Andersen $\mathbf{P}$ and Saltin B. Maximal perfusion of skeletal muscle in man. J Physiol 366: 233-249, 1985.

3. Brooks GA. Lactate: glycolytic product and oxidative substrate during sustained exercise in mammals-the "lactate" shuttle. In: Comparative Physiology and Biochemistry-Current Topics and Trends, edited by R Gilles. Berlin: Springer-Verlag, 1985, vol. A, p. 208-218.

4. Brooks GA. Mammalian fuel utilization during sustained exercise. Comp Biochem Physiol B Biochem Mol Biol 120: 89-107, 1998.

5. Brooks GA, Brown MA, Butz CE, Sicurello JP, and Dubouchaud H. Cardiac and skeletal muscle mitochondria have a monocarboxylate transporter MCT1. J Appl Physiol 87: 1713-1718, 1999.

6. Bünger R. Compartmented pyruvate in perfused working heart. Am J Physiol Heart Circ Physiol 249: H439-H449, 1985.

7. Carlson LA and Pernow B. Oxygen utilization and lactic acid formation in the legs at rest and during exercise in normal subjects and in patients with arteriosclerosis obliterans. Acta Med Scand 164: 39-52, 1959.

8. Chinkes DL, Zhang XJ, Romijn JA, Sakarai Y, and Wolfe RR. Measurement of pyruvate and lactate kinetics across the hindlimb and gut of anesthetized dogs. Am J Physiol Endocrinol Metab 267: E174-E182, 1994.
9. Dawson DM, Goodfriend TL, and Kaplan NO. Lactic dehydrogenase: function of the two types. Science 143: 929-993, 1964.

10. Essén B, Jansson E, Henriksson J, Taylor AW, and Saltin B. Metabolic characteristics of fibre types in human skeletal muscle. Acta Physiol Scand 95: 153-165, 1975.

11. Fletcher WM and Hopkins FG. Lactic acid in amphibian muscle. J Physiol 35: 16-309, 1907.

12. Freyschuss $\mathbf{U}$ and Strandell T. Limb circulation during arm and leg exercise in supine position. J Appl Physiol 23: 163-170, 1967.

13. Gollnick PD, Pernow B, Essén B, Jansson E, and Saltin B. Availability of glycogen and plasma FFA for substrate utilization in leg muscle of man during exercise. Clin Physiol 1: 27-42, 1981.

14. Hermansen $\mathbf{L}$ and Stensvold I. Production and removal of lactate during exercise in man. Acta Physiol Scand 86: 191-201, 1972.

15. Jorfeldt L. Metabolism of L(+)-lactate in human skeletal muscle during exercise. Acta Physiol Scand Suppl 338: 1-67, 1970.

16. Jorfeldt $\mathbf{L}$ and Wahren J. Human forearm muscle metabolism during exercise-quantitative aspects of glucose uptake and lactate production during prolonged exercise. Scand J Clin Lab Invest 26: 73-81, 1970.

17. Kanno T and Maekawa M. Lactate dehydrogenase M-subunit deficiencies: clinical features, metabolic background, and genetic heterogeneities. Muscle Nerve Suppl 3: S54-S60, 1995.

18. Landau BR and Wahren J. Nonproductive exchanges: the use of isotopes gone astray. Metabolism 41: 457-459, 1992.

19. Landau BR and Wahren J. Reply to the editor. Metabolism 42: 264-266, 1993.

20. Large V, Soloviev M, Brunengraber H, and Beylot M. Lactate and pyruvate isotopic enrichments in plasma and tissues of postabsorptive and starved rats. Am J Physiol Endocrinol Metab 268: E880-E888, 1995.

21. Lehman SL and Brooks GA. Obtaining a representative blood sample in lactate tracer studies. Horm Metab Res 22: 470-477, 1988.

22. Mygind E. Fibre characteristics and enzyme levels of arm and leg muscles in elite cross-country skiers. Scand J Med Sci Sports 5: 76-90, 1995.

23. Peuhkurinen KJ, Hiltunen JK, and Hassinen IE. Metabolic compartmentation of pyruvate in the isolated perfused heart. Biochem J 210: 193-198, 1983.

24. Rammal $\mathbf{K}$ and Ström G. The rate of lactate utilization in man during work and at rest. Acta Physiol Scand 17: 452-456, 1949.

25. Rasmussen HN, van Hall G, and Rasmussen UF. Lactate dehydrogenase is not a mitochondrial enzyme in human and mouse vastus lateralis muscle. J Physiol 541: 575-580, 2002.

26. Richter EA, Kiens B, Saltin B, Christensen NJ, and Savard G. Skeletal muscle glucose uptake during dynamic exercise in humans: role of muscle mass. Am J Physiol Endocrinol Metab 254: E555-E561, 1988.

27. Ryan WJ, Sutton JR, Toews CJ, and Jones NL. Metabolism of infused L(+)-lactate during exercise. Clin Sci (Colch) 56: 139-146, 1979.

28. Sahlin K, Fernström M, Svensson M, and Tonkonogi M. No evidence of an intracellular lactate shuttle in rat skeletal muscle. J Physiol 541: 569-574, 2002.

29. Schadewaldt P, Münch U, and Staib W. Evidence for the compartmentation of pyruvate metabolism in perfused rat skeletal muscle. Biochem J 216: 761-764, 1983.

30. Stainsby WN and Welch HG. Lactate metabolism of contracting dog skeletal muscle in situ. Am J Physiol 211: 177-183, 1966.

31. Stanley WC, Gertz EW, Wisneski JA, Neese RA, Morris DL, and Brooks GA. Lactate extraction during net lactate release in legs of humans during exercise. J Appl Physiol 60: 1116-1120, 1986.

32. Van Hall G. Correction factors for ${ }^{13} \mathrm{C}$-substrate oxidation at whole body and muscle level. Proc Nutr Soc 58: 979-986, 1999. 
33. Van Hall G. Lactate as a fuel for mitochondrial respiration. Acta Physiol Scand 168: 643-656, 2000.

34. Van Hall G, Calbet JAL, Søndergaard H, and Saltin B. Skeletal muscle carbohydrate and lactate metabolism after $9 \mathrm{wk}$ of acclimatization to 5,260 m. Am J Physiol Endocrinol Metab 283: E1203-E1213, 2002.
35. Van Hall G, González-Alonso J, Sacchetti M, and Saltin B. Skeletal muscle substrate metabolism during exercise. methodological considerations. Proc Nutr Soc 58: 899-912, 1999.

36. Wolfe RR. Radioactive and Stable Isotope Tracers in Biomedicine: Principles and Practice of Kinetic Analysis. New York: Wiley-Liss, 1992.

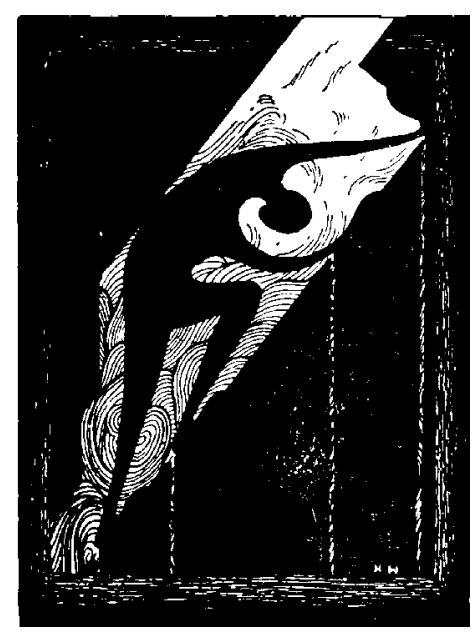

